2 Evidence for two stages of compressive deformation in a buried

\title{
basin of Mercury
}

${ }^{\text {a } I n s t i t u t o ~ d e ~ G e o c i e n c i a s ~(C S I C, ~ U C M), ~} 28040$ Madrid, Spain

${ }^{\mathrm{b}}$ Escuela Técnica Superior de Ingenieros en Topografía, Geodesia y Cartografía,

9 Universidad Politécnica de Madrid, Carretera de Valencia, km 7.5, 28031 Madrid, Spain

${ }^{\mathrm{c}}$ Departamento de Geodinámica, Facultad de Ciencias Geológicas, Universidad

12

13

14 


\section{Abstract}

2 The surface of Mercury shows abundant compressive tectonic landforms, including

3 lobate scarps, wrinkle ridges and high-relief ridges, which are different manifestations of

4 thrust faults, and long-wavelength topography variations, which could be the expression of

5 large scale folding. These landforms probably relate to planetary cooling, although other

6 factors such as mantle convection, tidal despinning or true polar wander could affect the

7 distribution, expression and orientation patterns of compressive features. In this work we

8 show that an area of smooth plains including a buried $\sim 500$-km-diameter impact basin

9 experienced two different stages of deformation. The younger deformation stage is

10 characterized by a set of NW-SE oriented wrinkle ridges affecting the smooth plains and

11 having the same approximate orientation as the wrinkle ridges and lobate scarps deforming

12 the surrounding terrains. The older set of tectonic structures consists of NE-SW oriented,

13 closely spaced, subparallel, quasi-rectilinear and low-relief ridges, partially buried by the

14 smooth plains material and crossed by the wrinkle ridges. Therefore, our results suggest

15 that several events occurred between both deformation stages: at least one stage of basin

16 filling; a change in stress orientation, an increasing in the wavelength and amplitude of

17 deformation, and maybe an increasing of the thickness of the deformed layer. Our

18 observations imply a complex stress history for compressive deformation, maybe

19 influenced by the internal and/or orbital/rotational history of Mercury, and are illustrative

20 of the complexity of tectonic history likely to have affected many or most other regions of

21 the planet.

22 Key words: Mercury; Tectonics; Terrestrial planets 


\section{Introduction}

The surface of Mercury shows abundant tectonic landforms, mostly indicating surface contraction (Strom et al., 1975; Dzurisin, 1978; Watters et al., 2009).

Compressional features on this planet mainly include lobate scarps, wrinkle ridges and high-relief ridges (for reviews of the tectonics of Mercury see Watters and Nimmo (2010) and Byrne et al. (2014)). Lobate scarps usually have an arcuate to linear form and an asymmetric cross section characterized by a steeply rising scarp face and a gently declining back scarp; wrinkle ridges are sinuous, morphologically complex (including front and back scarps), and generally located on volcanic plains; high-relief ridges are proportionally scarce and symmetric in cross section. Both types of features are interpreted as different surface manifestations of thrust faults, whose appearance depends of factors such like angle of fault dip and type of material on the deformed surface (Watters, et al., 2009; Watters and Nimmo, 2010; Ruiz et al., 2012; Byrne et al., 2014). Also, there is evidence of longwavelength topography variations, which affect even relatively young terrains as the northern smooth plains and Caloris basin, which could also be the expression of global contraction, and maybe large scale folding of Mercury (Zuber et al., 2012; Klimczak et al., 2013). The ubiquitous contraction observed is considered to be due to global planetary cooling (e.g., Strom et al., 1975), although it is debated if other factors such as mantle convection, tidal despinning or true polar wander affect the pattern of distribution and orientation (and maybe expression) of compressive features (e.g., Melosh and McKinnon, 1988; King, 2008; Matsuyama and Nimmo, 2009).

Many of the large, hundreds of kilometer long or even longer, thrust-fault related tectonic structures observed on the mercurian surface formed early (e.g., Watters and 
1 Nimmo, 2010; Ferrari et al., 2013; Banks et al., 2014), although tectonic deformation

2 continued throughout the planet history, and several lobate scarps, including small-scale

3 ones (of ten of kilometers of length or shorter), continued to be formed in relatively recent

4 times (Watters et al., 2009; Banks et al., 2012). Large-wavelength topographic deformation

5 affects the smooth plains, but their absolute timing is currently unclear, although it

6 postdates the emplacement of Calorian smooth plains (Balcerski et al., 2012; Dickson et al.,

7 2012; Solomon et al., 2012; Zuber et al., 2012),. However there is some information

8 suggesting a relatively early age, roughly contemporaneous to the formation of large lobate

9 scarps, for at least part of that large-scale topographic deformation (Ruiz et al., 2013).

10 Regardless of the absolute timing of deformation, improving our knowledge of the

11 relative timing between different deformation structures is very important in order to

12 understand the tectonic and stress history of Mercury. In this work we show that an area of

13 smooth plains close to the equator of this planet (Figure 1) including a nearly circular

14 buried basin (which is most probably an impact basin; Fassett et al., 2012), was affected by

15 two main deformation stages. These stages are characterized by two distinctive sets of

16 compressive tectonic features: (1) a NE-SW oriented set of quasi-rectilinear ridges, with

17 relatively low relief and that seem partially buried by the smooth plains material, and (2) a

18 NW-SE oriented set of large wrinkle ridges that affects the smooth plains and the low-relief

19 ridges. We also show that there was a change in the style, amplitude and orientation of most

20 of the tectonic structures, indicative of a complex stress history.

\section{$21 \quad$ [Figure 1]}




\section{$1 \quad 2$. Study area}

The area studied in this work is located in the equatorial region of Mercury, where

3 there is a nearly circular, $~ 500-\mathrm{km}$-diameter, basin centered around $4^{\circ} \mathrm{N}, 74^{\circ} \mathrm{E}$ (Figure 1).

4 Fassett et al. (2012) have interpreted this basin as a probable impact basin (and referred to it

5 as b12, nomenclature used in this work hereafter), but the term "probable" was used by

6 these authors in a very conservative sense, since they consider impact basins verified only

7 if they preserve a substantial part (at least 50\%) of the outer rim. In any case, the exact

8 origin of this basin is unimportant for our study, because the spatial pattern of the main

9 tectonic structures analyzed in this work is unaffected by basin limits or shape (see Section

103 ), although there are limited cases of some structural by impact craters walls.

11 The b12 basin is east of the Firdousi crater and its NNE limit is superimposed on the

$12 \mathrm{SW}$ rim of the Faulkner crater. The interior of the b12 basin is covered by smooth plains,

13 which also extend into the terrains between the craters Firdousi and Faulknernd, as well as

14 to the northwest of these three basins (Denevi et al., 2013). The approximate limits of the

15 basin can be observed in the stereo-derived topography of Preusker, et al. (2011; see their

16 Figure 6), where the plains covering the b12 basin floor exhibit the lowest elevation in the

17 area, roughly $1-2 \mathrm{~km}$ lower than the exterior smooth plains.

18 For this work, we have used mosaics created by the USGS using high-incidence

19 angle NAC images from MDIS instrument obtained during MESSENGER flybys. The

20 illumination conditions of flyby images are more useful for the present study than higher

21 resolution images from the orbital mission, because high incidence angle enhances the

22 shadows, which emphasize the relief of geologic structures. This is important when dealing

23 with tectonic structures, because it favors the identification of subtle structures. 


\section{3. Main tectonic structures}

Figure 2 shows the main tectonic features deforming the smooth plains in the b12

4 basin, and the crosscutting relations between them. The lobate scarp (Figure 2, L1)

5 superimposed on the east/southeast approximated location of the basin rim is the most

6 prominent feature in the zone; the basin rim is not clearly visible in this part, maybe due to

7 the deformation caused by the lobate scarp. The presence of tectonic structures (lobate

8 scarps, wrinkle ridges or even grabens) on mercurian impact structure rims is frequent (e.g.,

9 Fassett et al., 2012; Rothery and Massironi, 2013). The lobate scarp L1 has more than $1 \mathrm{~km}$

10 of relief (see Preusker, et al., 2011), and is complex (including several lesser scarps),

11 maybe indicating several pulses of activity in its formation or the superposition of several

12 individual structures.

$13 \quad$ [Figure 2]

14 The smooth plains inside the b12 basin are affected by a set of NW-SE oriented

15 wrinkle ridges (Figure 2, blue), which are not regularly spaced and have separations

16 between $\sim 50$ and $\sim 200 \mathrm{~km}$. These wrinkle ridges cross the northwest rim of the basin and

17 have the same approximate orientation as the wrinkle ridges and lobate scarps deforming

18 the surrounding terrains (see Byrne et al., 2014; see also the NW-SE oriented lobate scarp

19 in the SW corner of Figure 1). Wrinkle ridges are interpreted to be formed when blind

20 thrust faults deform superficial layers of stratified lava materials (e.g., Schultz, 2000), in

21 our study case the volcanic materials forming the smooth plains; this also explains that

22 smooth plains inside and northwest of the b12 basin are deformed into wrinkle ridges,

23 instead into lobate scarps, in a same stress regime. This set of structures includes a 
1 prominent wrinkle ridge (Figure 2, W1) located in the southwestern basin rim, which

2 probably was partly nucleated on the basin rim. This wrinkle ridge $\mathrm{W} 1$ continues out of the

3 b12 basin with the same general orientation as the whole set of NW-SE wrinkle ridges in

4 the study area. Wrinkle ridges nucleated on basin rims are frequent in other mercurian

5 basins (e.g., Fassett et al., 2012), and another example is seen on the western/northeastern

6 part of the b12 rim (Figure 2, W2), although in later case the wrinkle ridge cannot be

7 associated to the set of NW-SE wrinkle ridges.

8 A more subtle set of tectonic structures (Figure 2, red), recorded in the b12 basin

9 consists of subparallel, quasi-rectilinear and low-relief (according to shadow length) ridges,

10 NE-SW oriented, and regularly $(\sim 40 \mathrm{~km})$ spaced, which are crossed by the wrinkle ridges

11 and by the large lobate scarp L1 (see Figure 3a). These older structures, which hereafter we

12 denote as low-relief ridges, are much less prominent than wrinkle ridges and lobate scarps,

13 but they are clearly visible, form a well-defined pattern and are oriented nearly

14 perpendicular to the wrinkle ridges. Low-relief ridges have an arched cross-section relief,

15 although in some locations seem to be scarp-bounded (see Figure 3b), and they could be the

16 surface expression of folding and/or thrust faulting. Their spatial pattern does not seem

17 influenced by b12 basin geometry or limits, and that pattern must therefore be consequence

18 of a regional or global (rather than local) stress-field.

$19 \quad$ [Figure 3]

20 Two features maybe associated with the tectonic family of low-relief ridges are

21 visible just out of the NE basin rim (Figure 2), in the cratered materials just out the b12

22 basin. The northernmost structure ( $\mathrm{r} 1)$ of this pair is a ridge with the same orientation that

23 the NE-SW low-relief ridges and limited to the NW by a rectilinear (clearly structurally 
1 controlled) scarp marking the SE Faulkner crater wall. Their scarp limits the smooth plains

2 fill in the Faulkner crater interior, which suggests that this barrier-making scarp was formed

3 previously to basin filling. Although their orientation and width suggests that it could be

4 part of the low-relief ridges family, the SE wall of the ridge is affected by two impact

5 craters that make difficult a definitive assignation. The southernmost structure (r2) is a

6 short ridge with longer NE-SW dimension and with width similar to that of low-relief

7 ridges. It is located in cratered materials, bounded to the NW by an impact crater, and

8 ended to the NE by other impact crater, which renders difficult to be sure of a tectonic

9 origin. Both, $\mathrm{r} 1$ and $\mathrm{r} 2$ are well aligned with low-relief ridges, $\mathrm{r} 5$ and $\mathrm{r} 3$, respectively, inside

10 the basin, being better the alignment $\mathrm{r} 2-\mathrm{r} 3$. The feature $\mathrm{r} 2$ is not visible in the smooth plains

11 just east of the eastern branch of L1 in this area, where a buried impact crater is present: if

12 we accept this feature as a low-relief ridge, it could have been buried by smooth plains

13 materials and/or erased by the crater. The acceptable alignment between features separated

14 by L1 would be consistent with the very scarce shape distortion of a crater south of our

15 study area (see Figure 1) affected by this lobate scarp. Thus, our observations of r1 and r2,

16 although not definitive, suggest that the low-relief ridges predate the emplacement of the

17 smooth plains (because the connections between $\mathrm{r} 1$ and $\mathrm{r} 5$ and between $\mathrm{r} 2$ and $\mathrm{r} 3$ would

18 have buried), and that both features would be higher-standing than usual for low-relief

19 ridges, which would have avoided its complete burial by smooth plains materials. Finally,

20 there is another ridge south of the above mentioned (see Figure 2, r4), which is on smooth

21 plains materials and might also relate to the NE-SW low-relief ridges family (although it

22 includes a "non-rectilinear" portion), but the complex development of the L1 structure

23 precludes a definitive interpretation. 


\section{4. Stages of deformation}

Wrinkle ridges and low-relief ridges observed on the b12 basin (and surroundings)

4 represent two clearly different stages of deformation, related to two different stress

5 orientations. Not only do wrinkle ridges affect low-relief ridges, but both sets of structures

6 have clearly different orientation, organization and expression. Wrinkle ridges deform, and

7 therefore postdate, the smooth plains covering the b12 basin and part of the surroundings,

8 whereas low-relief ridges most probably predate the emplacement of the smooth plains (as

9 seen around the Faulkner crater). Thus, our observations suggest at least a stage of filling of

10 the b12 basin between these two deformation stages, after to the low-relief ridges but

11 previous to the wrinkle ridges. Low-relief ridges appear to be partly buried inside the basin,

12 as their expression is different to those just beyond the NE basin rim and on the Faulkner

13 crater rim.

The lobate scarp L1 thrusts at least one of the wrinkle ridges (see Figure 2; w3)

15 within the b12 basin, and therefore the lobate scarp (or the final moment of activity of this

16 scarp) represents the latest deformation seen in this area. However, the northern portions of

17 both L1 and its northern branch (which is labeled as L1n in Figure 2) have orientations

18 similar to the wrinkle ridges, and therefore their formation could have been

19 contemporaneous. In fact, L1n affects the smooth plains and has some characteristics

20 typical of wrinkle ridges, for example a higher scarp sinuosity and the presence of wrinkled 21 secondary scarps.

22 The evidence presented here for two deformation stages does not necessarily imply

23 that all deformation in the study area formed in two discrete pulses of activity, nor preclude 
1 other deformation moments or other stress fields acting in the study area. Indeed, there are

2 tectonic features in the study area, apart from L1, that cannot be easily related to any of the

3 two tectonic sets described above. For example there is a WNW-ESE structurally

4 controlled trough (see Figure 2, t1) just southeast of the b12 basin, whose relation with

5 other structures in the study area is unclear (although could have been affected by L1),

6 because of its different orientation. On a hand, the trough $\mathrm{t} 1$ is closely perpendicular to the

7 low-relief ridges. Because the low-relief ridges presumably formed perpendicular to the

8 direction of maximum compression, $\mathrm{t} 1$ would be closely (but not exactly) parallel to the

9 direction of maximum compression, and hence closely perpendicular to the least

10 compressive stress, for the deformation stage originating these ridges. Thus, $\mathrm{t} 1 \mathrm{might}$ be

11 tensile and formed under the same stress field. On the other hand, the appearance of t1 is

12 fresher than that of the low-relief ridges, which could suggest a younger age, and we cannot

13 therefore reach a definitive conclusion on this feature.

14 Also, there are several features with a "wrinkled" appearance in the south-central

15 part of the b12 basin (see Figure 2; wf). These features have some segments oriented

16 similarly to the NE-SW low-relief ridges and to some N-S oriented scarps on the NW-SE

17 wrinkle ridges, or even to L1. The wf structures could be wrinkle ridges whose different

18 orientations result from local conditions and maybe partial control of wrinkle ridges by

19 previous structures; for that reason, we consider this group of features as scarcely

20 informative for the purposes of this work, which rely on well-defined set of features and

21 orientations.

22 Thus, we consider that our identification of NE-SW low-relief ridges and NW-SE

23 wrinkle ridges, of their different relative age, and of the two different stress fields that they 
1 imply is not undermined by the presence of other deformation in the study area.

\section{5. Discussion and conclusions}

The two main stages of deformation described in the previous section formed structures with distinctive orientations, which implies a change in the regional stress

6 orientation between these stages, at least in the studied area. The deduced change in stress

7 orientation occurred in a lapse of time sufficient to permit the emplacement of the smooth

8 plains partly burying the low-relief ridges.

9 Stresses due to global contraction should produce a mostly isotropic distribution of 10 stress orientation, and hence a non-preferential orientation of tectonic features (Watters et 11 al., 2004); thus, some other factor driving or affecting tectonic deformation is needed to 12 explain our observations in the b12 area. Stresses related to despinning of an initially fast-

13 rotating planet (e.g., Melosh and McKinnon, 1988), and likely those due to thermal

14 convection in the thin mercurian mantle (King, 2008), would produce preferential

15 orientations of compressive features (although opposed, N-S and E-W, respectively,

16 according to those models) in the equatorial latitudes of Mercury; however, the temporal

17 change of the orientation of tectonic structures observed in this work occurred in the same 18 area.

19 Otherwise, true polar wander (e.g., Matsuyama and Nimmo, 2009) would seem a

20 natural way to produce changes in stress orientation in a given location. The magnitude of

21 stresses due to true polar wander depend on the magnitude of planetary flattening, which is

22 low for a slowly rotating planet such as Mercury (at present); thus, for true polar wander to

23 have significant influence on stress distribution in the b12 basin and surroundings, it would 
1 require a faster rotation when the deformation was formed. The angle between NW-SE

2 wrinkle ridges and NE-SW low-relief ridges is $\sim 80^{\circ}$; if we assume that maximum

3 compressive stresses are perpendicular to both types of structure, this angle could be

4 indicating the magnitude of true polar wander. However, this process is very difficult to be

5 sure of merely from the orientation of tectonic structures in a small area. A complete study

6 at planetary scale would be required to test this hypothesis (Watters and Nimmo, 2010).

7 Thus, the deformation observed in our study area could be due to the effect of a

8 combination of factors, including those discussed above and/or other, such as the pre-

9 existence of inhomogeneities or structures (see Watters and Nimmo, 2010), or the existence

10 of regional stress generation mechanisms. For example, the superposition of one or several

11 global stress mechanism with a stress field induced by global contraction could be

12 important in shaping the observed deformation patterns. In any case, our observations

13 contribute to a growing consensus that Mercury's compressive deformation has been long

14 and complex.

15 Also, there is a change in wavelength and probably in amplitude of deformation:

16 indeed, wrinkle ridges have a wider (although irregular) spacing and higher elevation (as

17 suggested by their stronger and darker shadows) than low-relief ridges. The spacing

18 difference suggests that the thickness of the deformed layer was increasing with time. This

19 could be due to a progressive cooling of the planet, and hence to a deepening of the brittle-

20 ductile transition, which could be the factor dominating the depth of deformation (e.g.,

21 Brown and Grimm, 1997). Low-relief ridges could even correspond to folding of a

22 relatively thin upper layer, in a certain sense a small-scale version of the large-scale folding

23 observed on Mercury. In any case, the original topography of the low-relief ridges could be 
1 obscured due to burial by smooth plains material.

2 Future work analyzing the pattern, orientation and expression of deformation, as

3 well as their temporal relations and changes across the mercurian geography, could be a

4 powerful means to constrain the stress and cooling history of Mercury, and to identify the

5 subjacent physical processes driving their evolution.

6

7 Acknowledgements

8 We thank the detailed reviews, comments, and suggestions from two anonymous

9 reviewers. JR work was supported by a contract Ramón y Cajal co-financed from the

10 Ministerio de Economía y Competitividad of Spain and the European Social Fund (ESF).

11

12

13

14

15

16

17

18

19

20

21

22

23 


\section{References}

2 Banks, M.E., et al., 2012. Stratigraphic relationships between lobate scarps and young

3 impact craters on Mercury: implications for the duration of lobate scarp formation.

$4 \quad$ Lunar Planet. Sci. Conf. 43st. Abstract 2684.

5 Banks, M.E., et al., 2014. Duration of activity on lobate-scarp thrust faults on Mercury.

6 Lunar Planet. Sci. Conf. 45st. Abstract 2722.

7 Balcerski, J.A., et al., 2012. Tilted crater floors: recording the history of Mercury's long-

8 wavelength deformation. Lunar Planet. Sci. Conf. 43st. Abstract 1850.

9 Byrne, P.K., Klimczak, C., Celâl Şengör, A.M., Solomon, S.C., Watters, T.R., Hauck II,

10 S.A., 2014. Mercury's global contraction much greater than earlier estimates. Nat.

$11 \quad$ Geos. 7, 301-307.

12 Brown, C.D., Grimm, R.E., 1997. Tessera deformation and the contemporaneous thermal

13 state of the plateau highlands, Venus. Earth Planet. Sci. Lett. 147, 1-10.

14 Denevi, B.W., et al., 2013. The distribution and origin of smooth plains on Mercury. J.

15 Geophys. Res. 118, 891-907.

16 Dickson, J.L., et al., 2012. Topographic rise in the northern smooth plains of Mercury:

17 characteristics from MESSENGER image and altimetry data and candidate modes of

18 origin. Lunar Planet. Sci. Conf. 43st. Abstract 2249.

19 Dzurisin, D., 1978. The tectonic and volcanic history of Mercury as inferred from studies of

20 scarps, ridges, throughs and other lineaments. J. Geophys. Res. 83, 4883-4906.

21 Fasset, C.I., et al., 2012. Large impact basins on Mercury: global distribution,

22 characteristics, and modification history from MESSENGER orbital data. J. Geophys.

23 Res. 117, E00L08, doi:10.1029/2012JE004154. 
1 Ferrari, S., Massironi, M., Marchi, S., Byrne, P.K., Klimczak, Cremonese, G., 2013. Age relations of the Rembrandt basin and scarp system, Mercury. Lunar Planet. Sci. Conf. 44st. Abstract 2102.

4 King, S.D., 2008. Pattern of lobate scarp in Mercury's surface reproduced by a model of mantle convection. Nat Geos. 1, 229-232.

Klimczak, C., et al., 2013. Insights into the subsurface structure of the Caloris basin, Mercury, from assessments of mechanical layering and changes in long-wavelength topography. J. Geophys. Res. 118, doi: 10.1002/jgre.20157. 
faults: keys to wrinkle ridge structure. J. Geophys. Res. 105, 12,035-12,052.

2 Solomon, S.C., et al., 2012. Long-wavelength topography change on Mercury: evidence and mechanism. Lunar Planet. Sci. Conf. 43st. Abstract 1578.

4 Strom, R.G., Trask, N. J., Guest, J. E., 1975. Tectonism and volcanism. J. Geophys. Res. $80,2478-2507$.

Watters, T.R., Nimmo, F., 2010. The tectonics of Mercury. In: Planetary Tectonics, Watters, T.R., Schultz, R.A. (Eds.), Cambridge Univ. Press. Cambridge, pp 15-80.

Watters, T.R., Robinson, M.S., Bina, C.R., Spudis, P.D., 2004. Thrust faults and the global contraction of Mercury. Geophys. Res. Lett. 31, L04071, doi:10.1029/2003GL019171.

11 Watters, T.R., Solomon, S.C., Robinson, M.S., Head, J.W., André, S.L., Hauck, S.A., Murchie, S.L., 2009. The tectonics of Mercury: The view after MESSENGER's first

14 Zuber, M.T., et al., 2012. Topography of the northern hemisphere of Mercury from MESSENGER laser altimetry. Science 336, 217-220.

16 


\section{$1 \quad$ Figure captions}

Figure 1. The smooth plains-covered basin studied in this work, which is located

3 west of the Firdousi crater and superimposed to the Faulkner crater. The area included in

4 the box is the same in the globe and in the context image. Note the NW-SE oriented lobate

5 scarp in the SW corner of the image, out of the box.

Figure 2. Different families of tectonic features observed in the studied basin. Black

7 lines indicate a lobate scarp (labeled L1) superimposed on the east/southeast of the basin

8 rim. Blue lines indicate a set of wrinkle ridges of orientation NW-SE that have the same

9 approximate orientation than the wrinkle ridges and lobate scarps deforming the

10 surrounding terrains (see, for reference, the lobate scarp in the SW corner of the Figure 1).

11 Red lines indicate an oldest set of tectonic structures consisting of subtle, subparallel,

12 quasi-rectilinear and low-relief ridges, NE-SW oriented and regularly spaced. Green lines

13 indicate a wrinkle ridge, nucleated on the basin rim, with a different orientation of those

14 marked in blue. Note that a same wrinkle ridge may be marked by lines indicating front and

15 back scarps. Label letters indicate different types of features: $\mathrm{L}=\mathrm{N}-\mathrm{S}$ large lobate scarp,

$16 \mathrm{~L} 1 \mathrm{n}=$ northern branch of $\mathrm{L} 1, \mathrm{~W}=$ wrinkle ridges, $\mathrm{wf}=$ indeterminate features with a

17 "wrinkled" appearance, $\mathrm{r}=$ low-relief ridges. Label numbers correspond to specific features

18 described in the text.

19 Figure 3. Details of the old low relief ridges showing: (3a) low relief ridges (red

20 arrows) crossed by wrinkle ridges (blue arrows) and by the large lobate scarp L1 (black

21 arrow); (3b) examples of scarp-bounded low-relief ridges (dark red arrows). 
Click here to download high resolution image

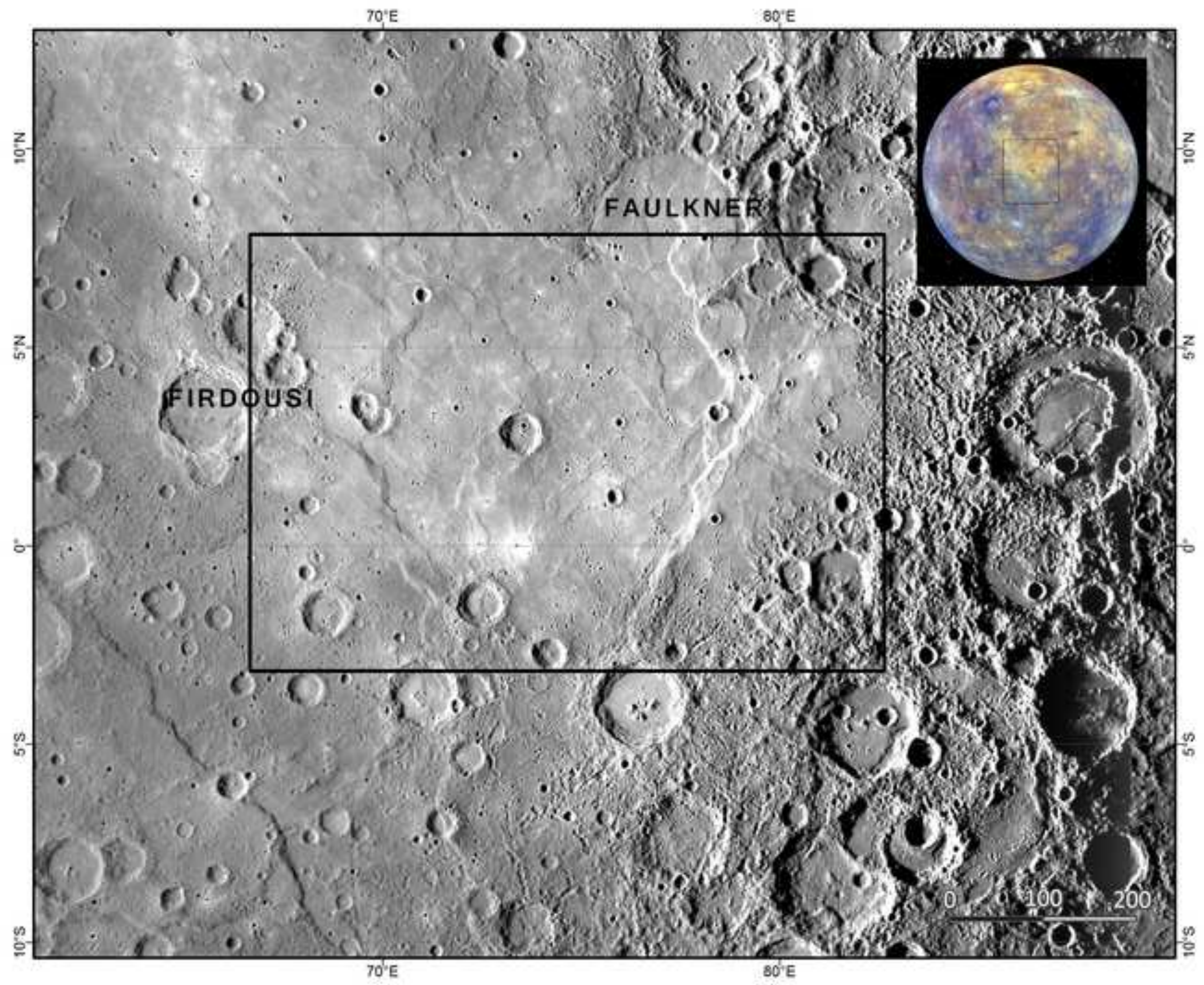




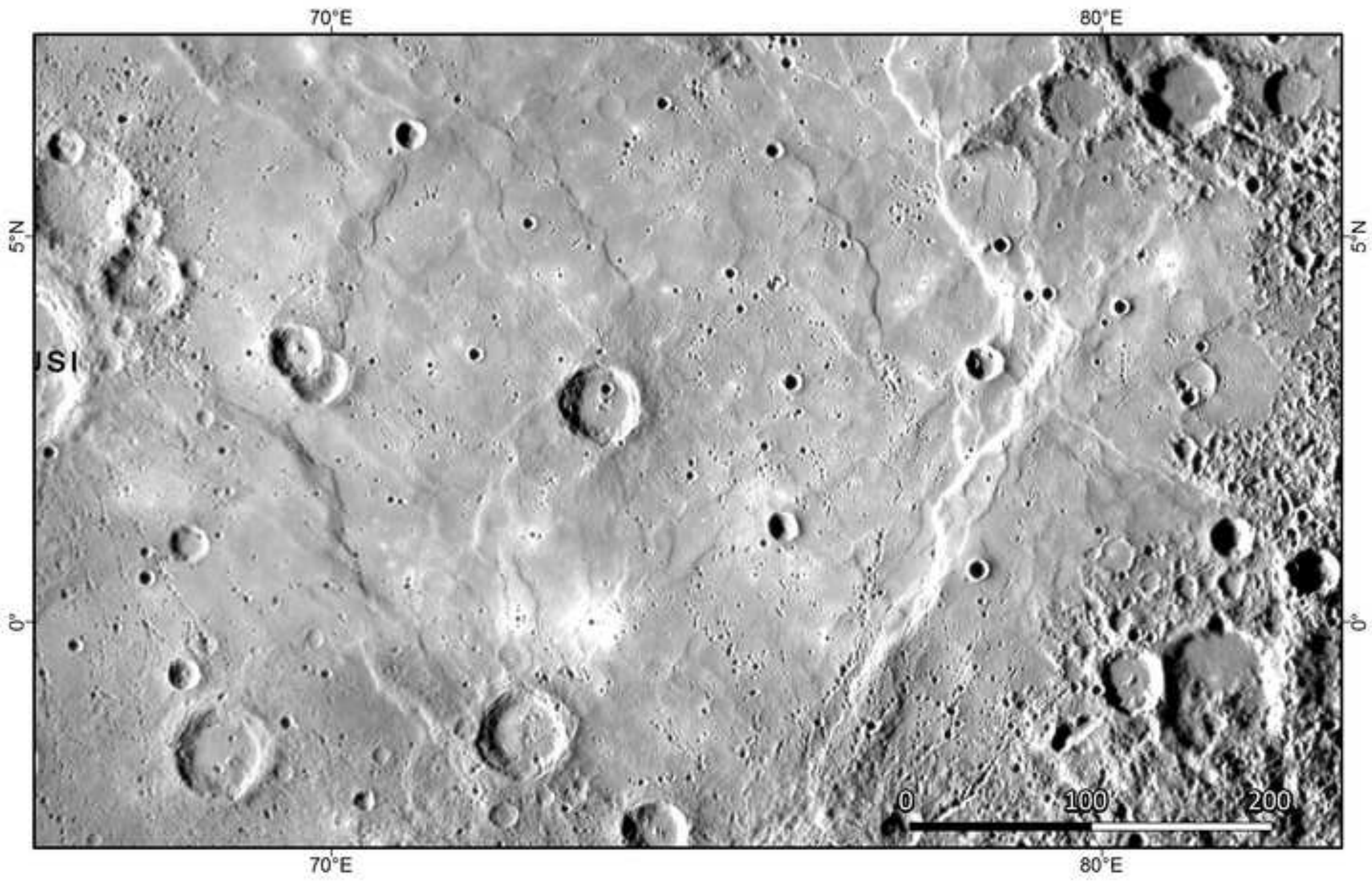




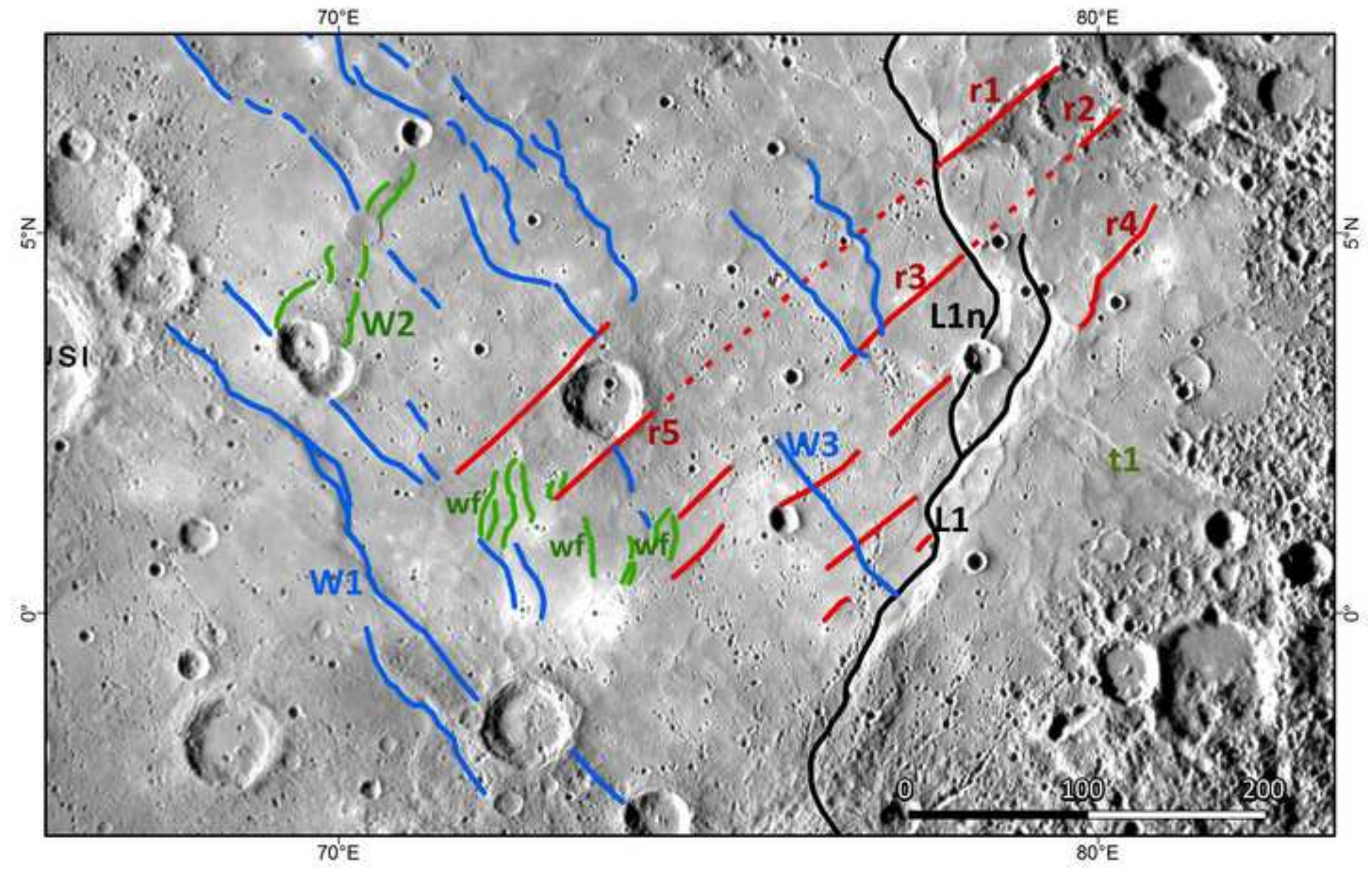


Click here to download high resolution image
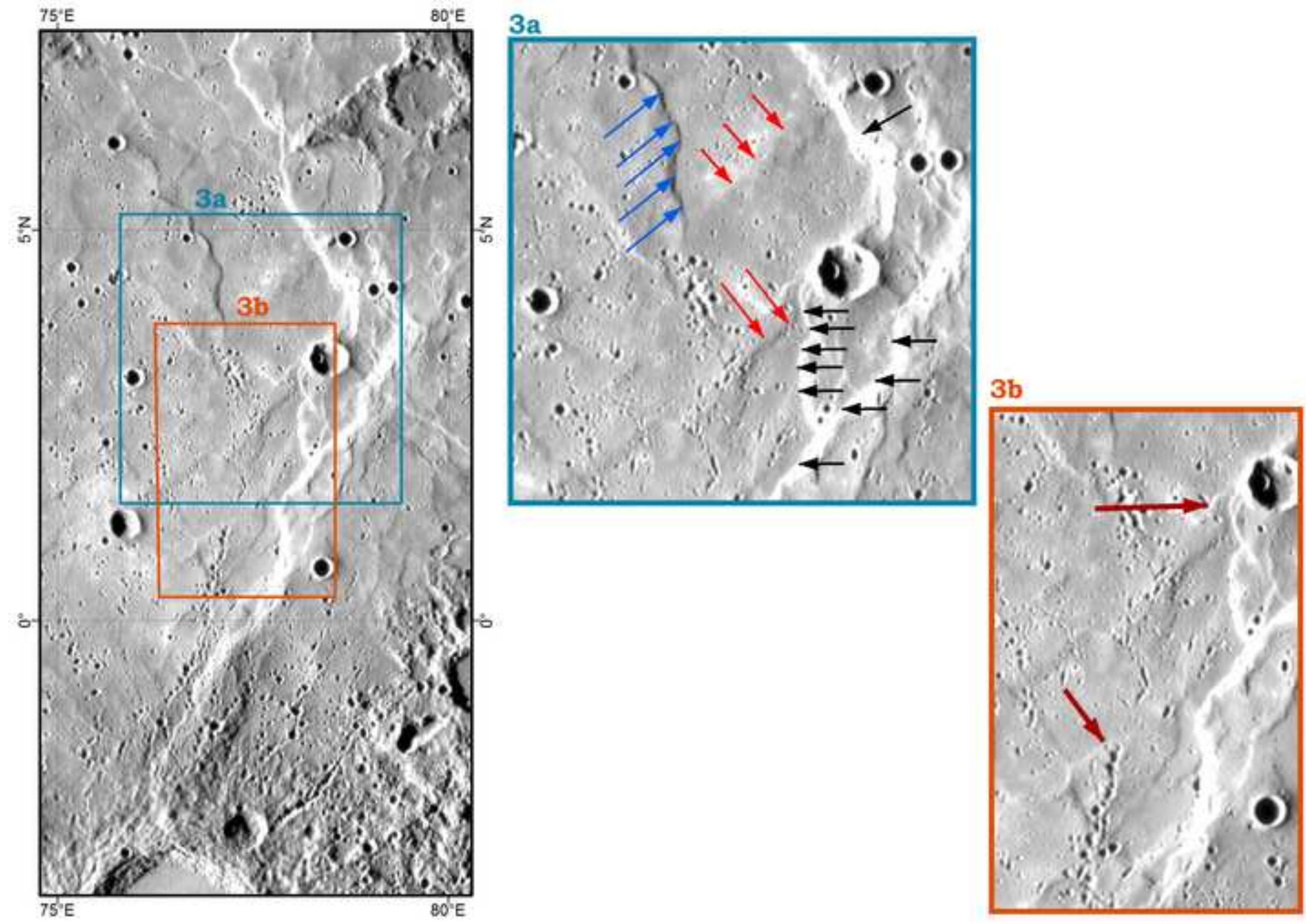